\section{Phenomena in High-Frequency Systems}

By August Hund. (International Series in Physics.) Pp. xv +642 . (New York and London : McGraw-Hill Book Co., Inc., 1936.) 36s.

THrs well-packed book of specialised information does not appreciably overlap the author's previous "High-frequency Measurements", and is intended to give a comprehensive and up-to-date discussion of the rapidly varying phenomena which the electrical communication engineer controls for useful ends, possibly often without understanding entirely the basic physical principles.

The thermionics of gaseous and vacuous valves introduces the subject matter, after a prefatory acknowledgment of the pioneer observers and developers of electromagnetic theory and electronics; generators of high-frequency power, modulators, demodulators, rectifiers and amplifiers receive detail treatment, and electro-striction is made an important division of the main subject; the serious aspects of electromagnetic theory then find a place, with applications to the more practical phenomena associated with propagation through ionized space and the technique adopted in directing radiated energy.

There are useful appendixes, but the last chapter on filters seems incomplete and redundant in view of the more comprehensive treatises now being issued. The author has a critical sense of the work of others, and his 'display' diagrams are specially helpful for the elucidation of the operation of complex valves and antennæ systems; the reviewer has still to find an explanation of what happens at the corners when a long wire is folded up to form a directive antenna.

L. E. C. H.

Die Allotropie der chemischen Elemente und die Brgebnisse der Röntgenographie

Von M. C. Neuburger. (Sammlung chemischer und chemisch-technischer Vorträge, herausgegeben von Prof. Dr. R. Pummerer, Neue Folge, Heft 30.) Pp. 106. (Stuttgart : Ferdinand Enke, 1936.) 9.30 gold marks.

The author gives an account of all the elements which have been supposed to exist in allotropic modifications and, by taking account of the latest methods of investigation, particularly X-rays, he decides which of them actually exhibit allotropy. The crystal forms of the allotropes are specified quantitatively, with very complete references to literature and diagrams.

Although the text is commendably brief and clear, it fails in one or two cases to supply information which the reader would like to have, such for example \&s to whether explosive antimony is an allotropic form or not. The author, in fact, is concerned almost entirely with the results of X-ray analysis, and where this is not applicable he tends to remain silent. In its field, the book is of very considerable value and arves a reliable guide through a large mass of data, much of it contradictory. It states clearly in which cases allotropy has been established and where it has not, and in the doubtful cases it presents the ovidence in an unprejudiced way.
Soils :

their Origin, Constitution and Classification; an Introduction to Pedology. By Prof. G. W. Robinson. Second edition. Pp. xvii $+442+5$ plates. (London : Thomas Murby and Co., 1936.) 20s, net.

Prof. Robrnson's novel treatment of soil science evidently 'met a long felt want', for a new edition has been required in less than four years. The rapidly developing subject of pedology has many more intimate links with other branches of science than had the older agricultural chemical treatment of soils. At the same time, it bears more closely on those general questions of land classification and utilisation which are becoming increasingly urgent. Surveys and planning must be preceded by careful study of the objects to be classified and their relationships to environmental and historical factors. Prof. Robinson's book shows how far the modern science of soils has been able to go in the interpretation of the formation and behaviour of soils. The geographical and genetic aspects are kept in the foreground throughout, while the more purely technical and agricultural ones are treated very briefly indeed. The book can be strongly recommended to workers in many branches of natural and applied science.

In the new edition the bibliography has been increased and the illustrations greatly improved. Quite recent work on the clay complex, base exchange and soil moisture are fully discussed, space having been gained by omitting the appendix on methods of analysis, which were well handled in $\mathrm{Mr}$. C. $\mathrm{H}$. Wright's recent book.

Official Year Book of the Commonwealth of Australia No. 28, 1935. Prepared by E. T. McPhee. Pp. xxxi+971. (Commonwealth Bureau of Census and Statistics, Canberra.) (Canberra: Commonwealth Government Printer, 1936.) 5s.

THE new issue of this valuable year book is planned on the usual lines, and even if the call for economy still curtails the size of the volume and curbs the desire of the editor in the presentation of available data, the scope is so comprehensive that little of real importance can have been omitted.

After a summary of the history of the Commonwealth, with the Act of Constitution in full, there follows a chapter on the climate and meteorology provided with statistics, graphs and a rainfall map. Among the many chapters of administrative and financial statistical detail, there is especially full treatment of vital statistics as disclosed in the census of 1933. It appears that the birth-rate in Australia has fallen to the relatively low figure of $16 \cdot 4$ per 1,000 from $27 \cdot 1$ in 1901. If this is low, the death-rate of $9 \cdot 3$ per 1,000 is one of the lowest in the world, so that the natural increase is still higher than in European States excluding Russia, the Netherlands, Spain and Italy. Increase by immigration, which was so high as 32,000 in 1927 , fell to about 1,000 in 1934 after four years of actual loss by emigration. The volume has full particulars of agricultural production and mineral output. New Guinea is included in the survey. There is a useful bibliography. 